\title{
Magnet Coil Shorted Turn Detector
}

\author{
John A. Dinkel and James E. Biggs
}

Fermi National Accelerator Laboratory

P.O. Box 500, Batavia, Illinois 60510

March 1994 


\section{Disclaimer}

This report was prepared as an account of work sponsored by an agency of the United States Government. Neither the United States Government nor any agency thereof, nor any of their employees, makes any warranty, express or implied, or assumes any legal liability or responsibility for the accuracy, completeness, or usefulness of any information, apparatus, product, or process disclosed, or represents that its use would not infringe privately owned rights. Reference herein to any specific commercial product, process, or service by trade name, trademark, manufacturer, or otherwise, does not necessarily constitute or imply its endorsement, recommendation, or favoring by the United States Government or any agency thereof. The views and opinions of authors expressed herein do not necessarily state or reflect those of the United States Government or any agency thereof. 


\section{Magnet Coil Shorted Turn Detector}

\section{Introduction:}

The Magnet Coil Shorted Turn Detector has been developed to facilitate the location of shorted turns in magnet coils. Finding these shorted turns is necessary to determine failure modes that are a necessary step in developing future production techniques. Up to this point, coils with shorted turns had the insulation burned off without the fault having been located. This disassembly process destroyed any chance of being able to find the fault.

In order to maintain a flux balance in a coupled system such as a magnet coil, the current in a shorted turn must be opposed to the incident current. If the direction of the current in each conductor can be measured relative to the incident current, then the exact location of the short can be determined. In this device, an AC voltage is applied to the magnet under test. A small hand held B-dot pickup coil monitors the magnetic field produced by current in the individual magnet conductors. The relative phase of this pickup coil voltage is compared to a reference signal derived from the input current to detect a current reversal as the B-dot pickup coil is swept over the conductors of the coil under test. This technique however, is limited to only those conductors that are accessible to the hand held probe.

A simplified schematic and mathematical model of a magnet coil with a shorted turn is illustrated in Figure 1.

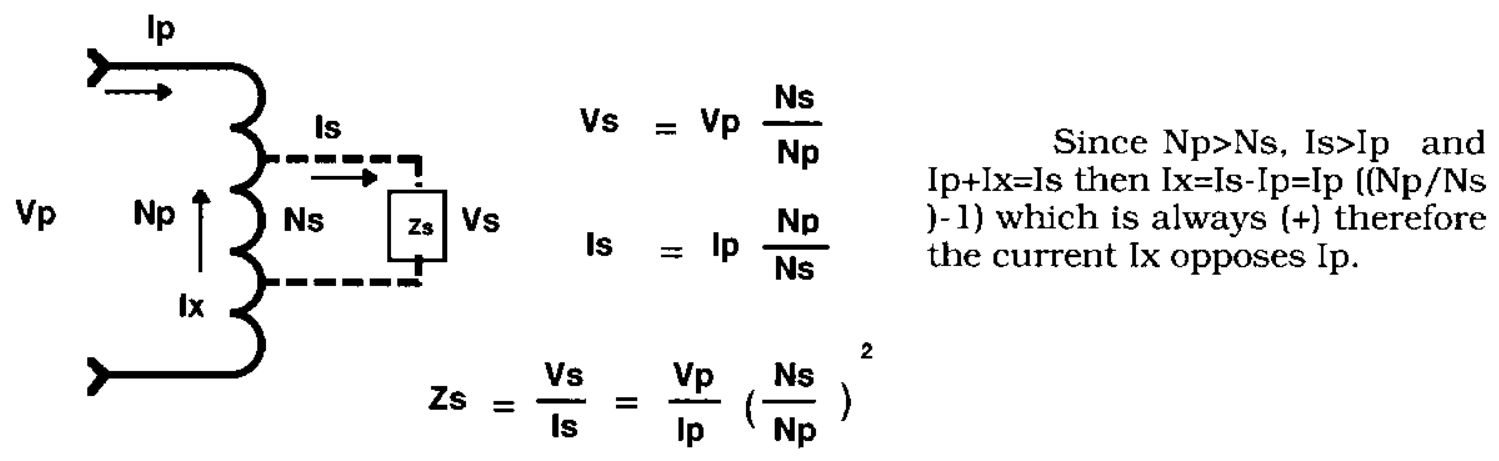

Figure 1. Magnet Coil with Shorted Turn

\section{B-dot Pickup Coil:}

The hand held B-dot pickup coil used in monitoring the magnet field consists of four 50 turn layers of 34AWG magnet wire wrapped around 23 laminations of 3.01" $\mathrm{x}$ $.500^{\prime \prime} \mathrm{x} .002 "$ silicon steel. Each layer is insulated from adjacent layers with Teflon tape and mounted in a G-10 frame for support as seen in Figure 2. The pickup coil is then wrapped with Kapton tape before being surrounded with copper foil to form a Faraday shield. A small gap is left in the Faraday shield to allow for field pickup. This entire assembly is then wrapped with Kapton tape. The pickup coil output leads go through small holes in the Faraday shield to a Twinax connector mounted on the end of the Teflon handle. 

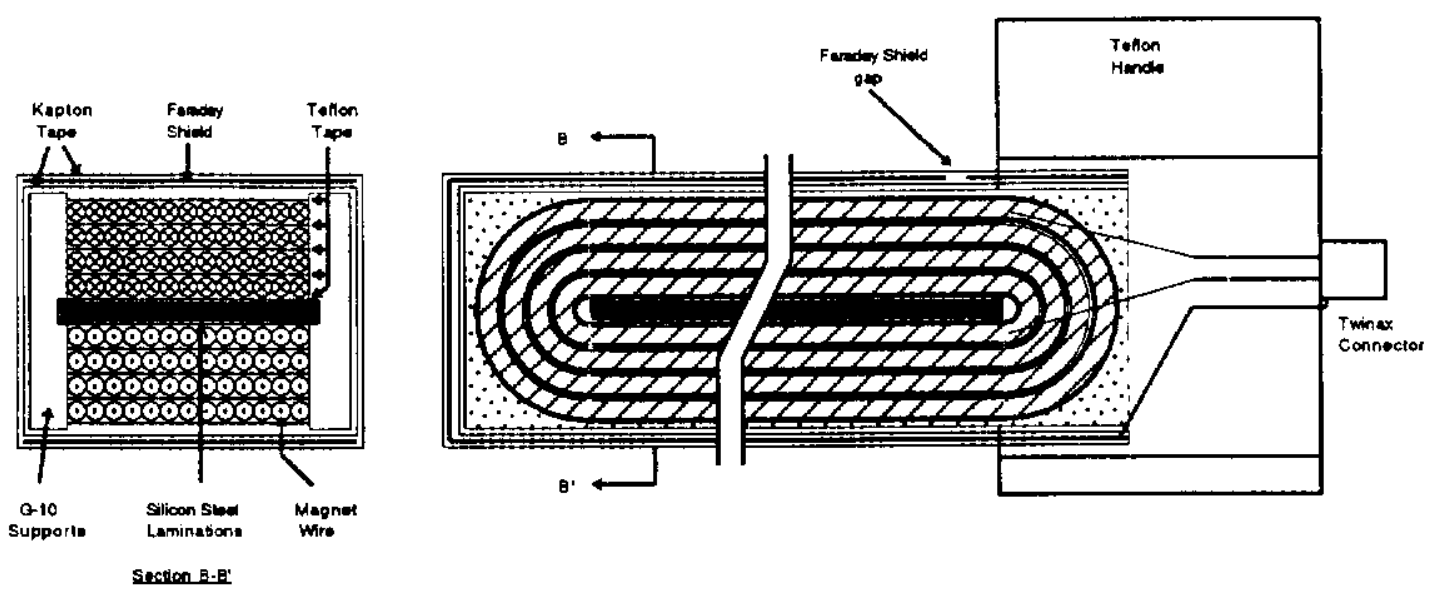

Figure 2. B-dot pickup coil construction

The B-dot pickup coil generates a voltage when the lines of flux produced by the coil under test are coupled into its windings. This is best achieved when the pickup coil windings are parallel to those of the coil under test. Pickup coil orientation with respect to the coil under test is demonstrated in Figure 3.

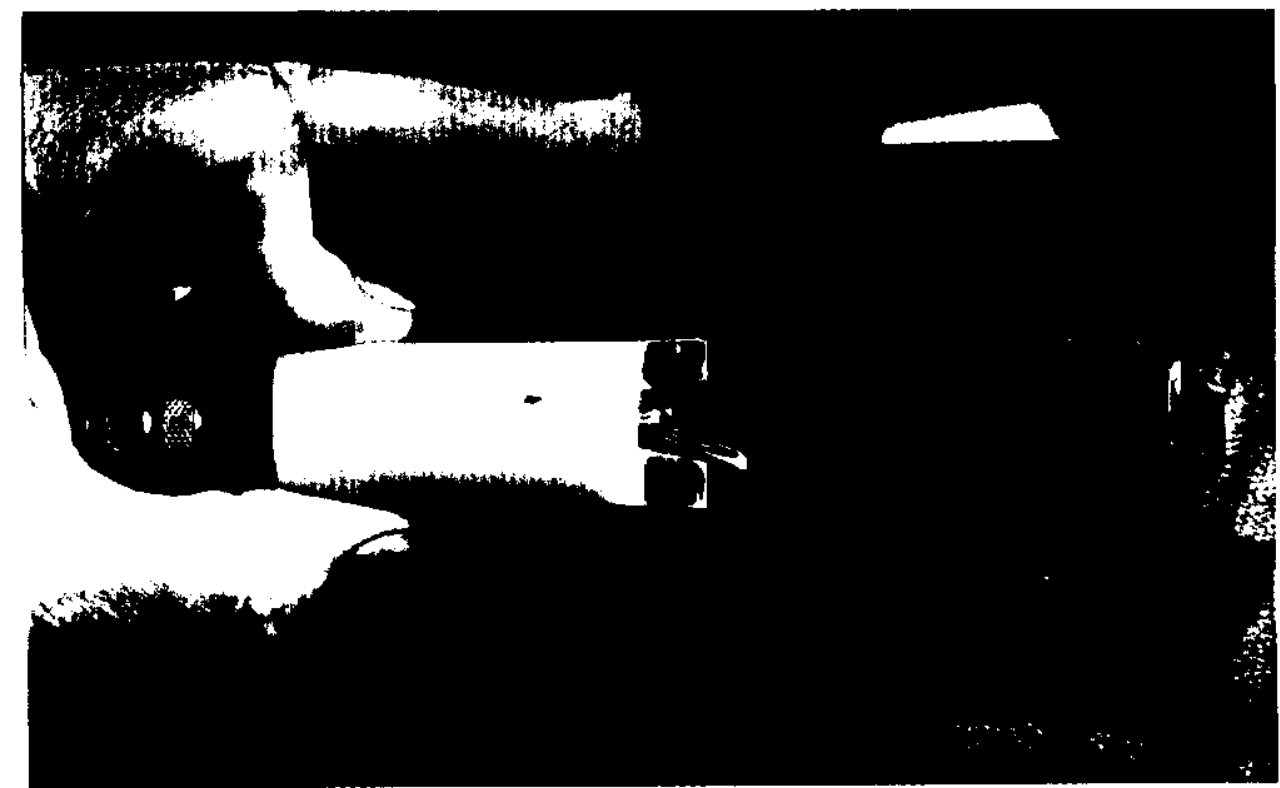

Figure 3. Pickup Coil Orientation

\section{Sensing Electronics:}

The Sensing Electronics is used to compare the phase between the B-dot pickup coil and the AC Power Source signals. This comparison is done with a four-quadrant multiplier I.C. as shown in Figure 4. When the integrated signal from the B-dot pickup coil and the AC Power Source current are in phase. the four-quadrant multiplier has a positive output. When a fault is found, the output of the four-quadrant multiplier goes negative due to the current reversal sensed by the B-dot pickup coil. The four-quadrant multiplier output goes to a fault comparator which drives both an LED and Sonalert type device indicating the location of the shorted turn. The audio indication of the presence of a short will free the operator from the constant need to monitor the fault LED on the Sensing Electronics enclosure. The Sonalert indicator can be switched off if this type of indication is not desired. The fact that we are looking for only a polarity change from the four-quadrant multiplier means that the amplitude of the input signals 
are not critical.

Since the B-dot pickup coil, at a given frequency, generates a signal proportional to the derivative of the magnet flux being coupled to its windings from the coil under test, its output must be integrated before being applied to the four-quadrant multiplier. This integrated signal also drives a signal level comparator that indicates with an LED, that the signal strength of the field generated from the AC Power Source current is large enough to be detected by the Sensing Electronics. This LED lights only when a signal is detected with the scanning of the pickup coil across the conductors of the magnet coil under test. This LED lights independently of the polarity of the incoming signal.

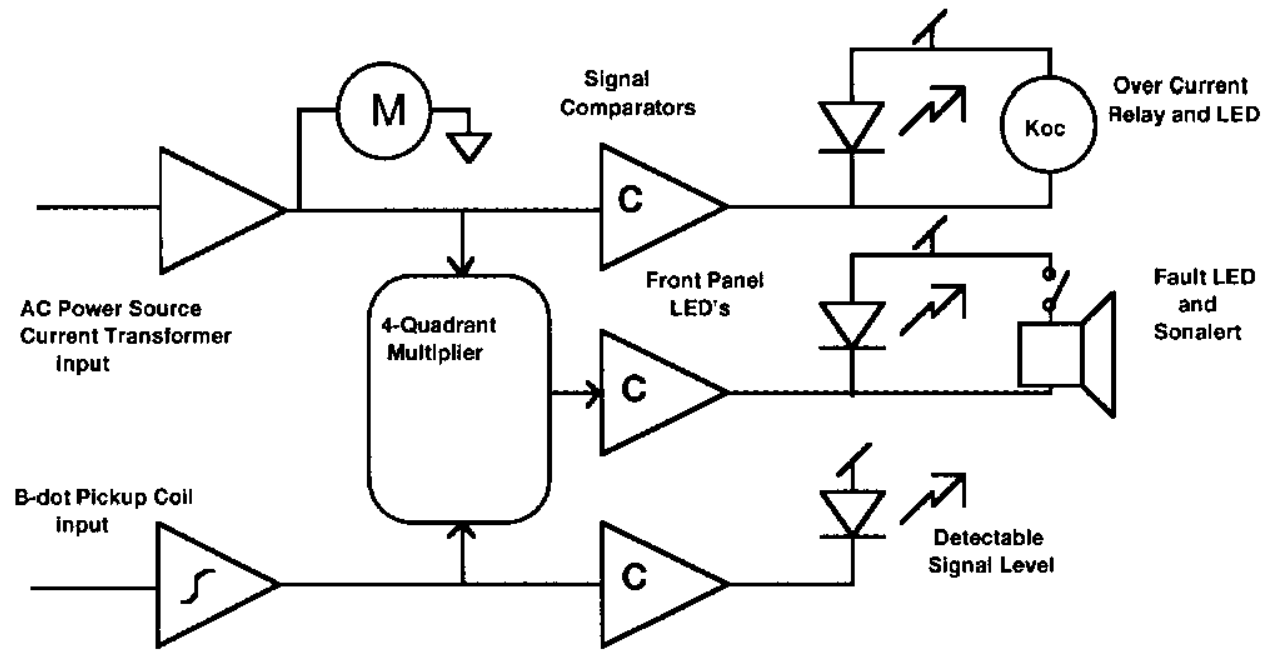

Figure 4. Sensing Electronics

\section{AC Power Source:}

The AC Power Source supplies the reference signal being compared to the integrated B-dot pickup coil signal from a calibrated current transformer that is amplified and applied to the four-quadrant multiplier. In addition, the amplified reference signal drives a front panel meter that gives the user a visual indication of the current level being applied to the coil under test. The reference signal also feeds a signal level comparator set to trip an over current relay should the $\mathrm{AC}$ Power Source current limit be exceeded. This latched overcurrent relay contact interlocks the AC Power Source. It must be reset after a trip through a front panel push-button switch located on the Sensing Electronics enclosure. A red LED in the Sensing Electronics also indicates when the overcurrent trip occurs.

The output capacity of the AC Power Source is $6.3 \mathrm{v}$ at $20 \mathrm{~A}$. This comes from a 6.3 volt filament transformer whose primary is connected to a variac which allows the operator to control the amount of current being supplied to the coil under test. The output leads are attached to the coil under test with large "Alligator" clamps. Once the AC Power Source has been used to supply current to the coil under test, the variac should be returned to zero before the leads are removed because of the stored energy in the magnet coil. The Power Source has two front panel neon indicators. One is used for a power on indication and the second indicates that an overcurrent trip has occurred.

Figure 5 illustrates a simplified schematic of the AC Power Source. 


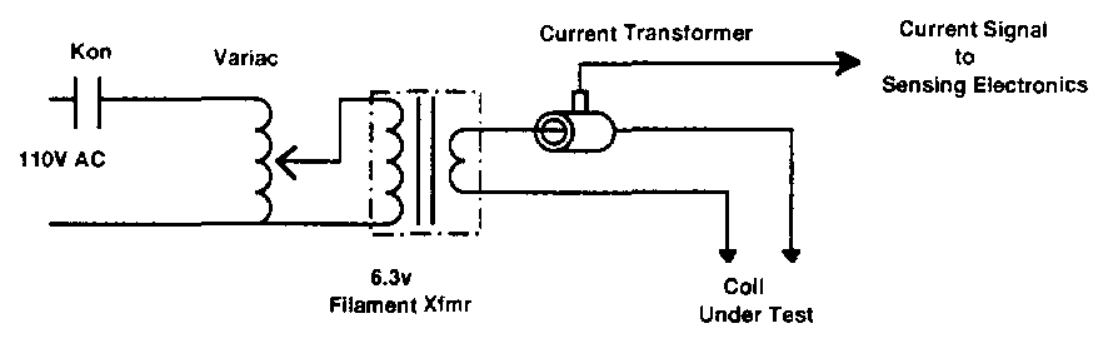

Figure 5. AC Power Source

Figure 6 illustrates the B-dot pickup coil, Sensing Electronics and the AC Power Source.

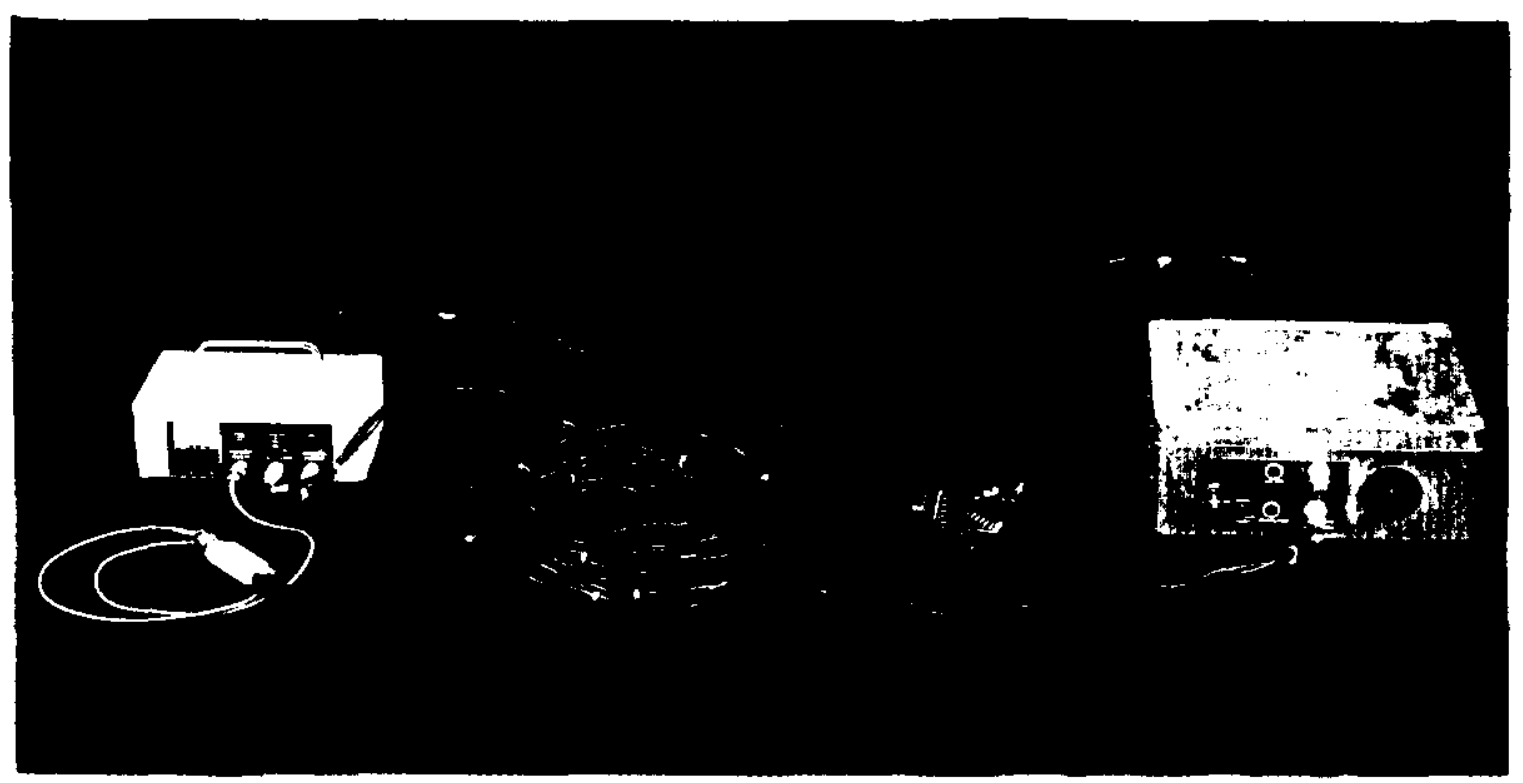

Figure 6. Magnet Coil Shorted Turn Detector 